\title{
Addressing disparities in patients' opportunities for and competencies in shared decision making
}

\author{
Naomi Q P Tan, Robert J Volk
}

Department of Health Services Research, The University of Texas MD Anderson Cancer Center, Houston, Texas, USA

\section{Correspondence to}

Professor Robert J Volk, Department of Health Services Research, The University of Texas MD Anderson Cancer Center, Houston, TX 77030, USA; bvolk@mdanderson.org

Accepted 15 June 2021

\section{Linked}

- http://dx.doi.org/10.1136/ bmjqs-2020-012786.R3

\section{Check for updates}

(C) Author(s) (or their employer(s)) 2021. No commercial re-use. See rights and permissions. Published by BMJ.

To cite: Tan NQP, Volk RJ. BMJ Qual Saf Epub ahead of print: [please include Day Month Year]. doi:10.1136/ bmjqs-2021-013533
In this issue of BMJ Quality \& Safety, Birkeland and colleagues ${ }^{1}$ conducted an online experiment where 6756 male healthcare users in Denmark were randomised to view 1 of 30 case vignettes of possible scenarios they may encounter when making a decision about prostate cancer screening. In this study, 30 case vignettes were created that varied by level of patient involvement in making the decision, screening choice and downstream cancer outcomes. ${ }^{1}$ Despite using hypothetical scenarios and limiting the sample to men, this study yielded important insights into the impact of shared decision making (SDM) on peoples' reports of satisfaction with their care. ${ }^{12}$ Birkeland and colleagues ${ }^{1}$ found that participants were generally more satisfied with scenarios where the doctor was in favour of PSA testing, but greatest levels of satisfaction with their healthcare were observed when there was SDM, use of a decision aid, and dialogue with their doctor. Interestingly, this remained the case even in scenarios where patients had poor outcomes, suggesting that ownership of the decision to screen is important in acceptance of poor clinical outcomes. ${ }^{1}$ These findings suggest that a high-quality SDM process, supported by the use of decision aids, may be protective against regret for patients who experience poor outcomes following a decision. More research with patients facing difficult, preference-sensitive healthcare decisions is needed to explore this hypothesis.

Birkeland and colleague's ${ }^{1}$ discussion highlights the prior mixed research regarding associations between SDM and patient satisfaction. Crucially, they suggest that one possible explanation for the mixed findings may have been the ceiling effects for patient satisfaction ${ }^{1}$; most patients tend to be satisfied with their care even if no SDM is involved. This finding aligns with previous research that found that while patients desired some level of involvement in decision making, they did not expect SDM with their doctor and may not be aware of opportunities for SDM. ${ }^{3}$ As providers move towards a patient-centred model of care, how do we engage patients in SDM and make SDM normative for both patients and providers in order to ensure that expectations between patient and provider in the medical encounter are aligned? Some patients may not expect SDM from their provider, may not be aware that SDM has benefits for them beyond usual care, or may not have the skills or competencies to confidently initiate or engage in SDM with their provider.

Some scholars have also expressed concern that SDM may exacerbate health disparities experienced by socially disadvantaged groups, which include characteristics such as having limited education, being uninsured, being female, having an immigrant status, being non-white, having limited English proficiency and having low literacy. ${ }^{2}{ }^{4}$ Although all patients could benefit from more SDM with their providers, socially disadvantaged groups may be disproportionately impacted if they have underdeveloped skills or competencies or limited opportunities to effectively engage in SDM with their provider, and hence may experience health disparities such as poor quality of care or lower patient satisfaction. ${ }^{56}$ Indeed, Towle et $a l^{7}$ emphasised that patients should possess certain skills for SDM so that the responsibility for initiating SDM does not rest with the provider alone. Greater patient involvement also means greater responsibility for the patient to understand information and to participate in decision making. 
While there are a number of studies on building SDM competency among providers ${ }^{8-10}$ and use of decision aids to facilitate the SDM process, there appear to be fewer interventions or tools that enhance similar SDM competencies in patients. Towle et $a l^{7}$ for instance, have begun to define a list of competencies for patients that may be useful in SDM, which includes skills such as clear articulation of health problems and expectations, communication with the provider and ability to evaluate information. In addition, other qualities or skills such as communication efficacy (ie, a belief in one's ability to communicate with a provider about a health issue ${ }^{11}$ ) and numeracy skills (ie, the ability to comprehend numerical information ${ }^{12}$ ) can also affect the degree of patient involvement in the SDM process and risk comprehension. ${ }^{12}$ An equally important competency is the ability to minimise bias in decision making. An important finding in Birkeland and colleagues"1 paper is that participants were less satisfied with scenarios where a healthcare provider nudged them away from screening. Two factors may explain this finding: (1) conventional wisdom that early detection of cancer is always best and has few if any downsides or risks ${ }^{13}{ }^{14}$; and (2) action bias, where taking any action is preferred over what is seen as doing nothing. ${ }^{15}$ Future research can focus on identifying the necessary skills and competencies for patients to effectively engage in SDM and consider educational components for patients that could be incorporated in existing interventions to overcome disparities in engaging in SDM.

One way of instilling SDM competencies in patients and overcoming disparities in ability to engage in SDM is through the use of educational narratives, which can take the form of personal testimonials or entertainment narratives (eg, telenovelas and soap operas). These may be disseminated to patients as part of a patient decision aid prior to their SDM visit with the provider (eg, as an educational video in a web-based patient decision aid). The International Patient Decision Aids Standards Collaboration recently conducted a series of reviews to evaluate the utility of including patient narratives in patient decision aids. ${ }^{16} 17$ They concluded that there should not be a blanket recommendation for patient narratives to be included in patient decision aids due to mixed findings on their effectiveness and the potential to bias patients' judgement and decision making. ${ }^{17}$ However, the review acknowledged that narratives can be a powerful tool to communicate information and to address issues of health literacy. ${ }^{17}$ Narrative persuasion research has argued that narratives can provide conversational scripts for the audience to engage in interpersonal discussion by showing characters in the story successfully modelling the behaviour. ${ }^{18} 19$ For instance, a study by Moyer-Gusé et $a l^{20}$ found that when audiences identified with the character in the narrative that had a conversation about safe sex behaviour, they had greater intentions to engage in safe sex discussions. Similarly, a narrative with a character that effectively engages in an SDM discussion with their provider can provide conversational scripts for the audience to use in their own SDM encounters, hence increasing communication efficacy. In addition, the use of narratives is proposed to be particularly effective compared with other message types (eg, didactic messages) for populations that have low literacy. ${ }^{21}$

Current SDM principles and patient decision aids are based on the rational model of choice behaviour. ${ }^{22}$ In the rational model of choice behaviour, the decision maker engages in cognitive processes such as considering the different choices, weighing risk and benefits and considering probabilities of a certain action occurring. ${ }^{22}$ There is also an implicit assumption that interventions

Table 1 Summary of disparities in the use of SDM and potential solutions

\begin{tabular}{|c|c|c|}
\hline Target group & Disparities in the use of SDM & Potential solutions \\
\hline Patients & $\begin{array}{l}\text { Patient barriers to engagement in SDM with providers (eg, } \\
\text { low literacy skills, low numeracy skills and low communication } \\
\text { efficacy) }\end{array}$ & $\begin{array}{l}\text { Educational interventions that enhance SDM competencies, } \\
\text { for example, a narrative that provides information in an easily } \\
\text { digestible format and with conversational scripts for patients to } \\
\text { initiate or engage providers in SDM discussions }\end{array}$ \\
\hline \multirow[t]{2}{*}{$\begin{array}{l}\text { Researchers/developers } \\
\text { of decision tools }\end{array}$} & $\begin{array}{l}\text { Lack of understanding of SDM needs and preferences of } \\
\text { cultural minorities }\end{array}$ & $\begin{array}{l}\text { More research examining attitudes towards and perspectives } \\
\text { of SDM among cultural minorities, and their needs and } \\
\text { preferences }\end{array}$ \\
\hline & Lack of culturally appropriate patient decision aids & $\begin{array}{l}\text { Go beyond cultural adaptation of existing tools or language } \\
\text { translation of a tool, and engage in the design of culturally } \\
\text { appropriate patient decision aids with community involvement } \\
\text { in the design process }\end{array}$ \\
\hline Providers & $\begin{array}{l}\text { Provider barriers to engagement in SDM with patients who are } \\
\text { cultural minorities (eg, limited cultural knowledge or cultural } \\
\text { competence skills) }\end{array}$ & $\begin{array}{l}\text { Building provider's skills in cultural competence and } \\
\text { development of culturally appropriate patient decision aids that } \\
\text { can be used by providers during the SDM consultation }\end{array}$ \\
\hline System level & $\begin{array}{l}\text { System-level barriers to supporting patients who are socially } \\
\text { advantaged and/or are cultural minorities during the SDM } \\
\text { process }\end{array}$ & $\begin{array}{l}\text { Increasing support for patients who are socially advantaged } \\
\text { and/or are cultural minorities by including translators or patient } \\
\text { navigators in the SDM process }\end{array}$ \\
\hline
\end{tabular}

SDM, shared decision making. 
or decision aids designed for a general population are able to address the needs of cultural minorities, and there is a lack of emphasis on understanding the SDM needs and preferences of cultural minorities. ${ }^{23}$ This may exacerbate health disparities experienced by cultural minorities by limiting their opportunities or willingness to engage in SDM with their providers if the SDM process is not culturally sensitive or if the patient decision aids provided to them are not culturally relevant or informed. Indeed, existing research suggests that current SDM principles may not fully reflect the perspectives of cultural minorities. For instance, a study conducted with African-American patients found that SDM was conceptualised in different ways and that African-Americans patients prioritised certain aspects of the SDM process, such as telling their story and feeling heard, as well as information sharing by both doctor and patient. ${ }^{24} \mathrm{~A}$ systematic review of SDM for cancer care among ethnic minorities in the USA found that factors such as level of acculturation and fatalistic beliefs about cancer (based on spiritual and cultural beliefs) impacted decision making. ${ }^{25}$ In addition, family or community members were important in the decision-making process, leading the authors to suggest expanding the traditional SDM model beyond patient and provider. ${ }^{25}$ These studies highlight a space for future research to examine whether current SDM principles apply to cultural minorities, particularly understudied groups such as Asian Americans in the USA, and how their understanding of SDM, attitudes towards SDM, and preferences for SDM differs based on their cultural context. Additionally, reviews of patient decision aids also suggest that few are culturally targeted or appropriate. ${ }^{26}$ Along with an understanding of how minority populations view SDM, patient decision aids can be designed to be culturally targeted or appropriate while reflecting the norms, values, preferences and needs of minority populations. ${ }^{23}{ }^{27}$ Please see table 1 for a summary of the disparities in patients' engagement in and use of SDM and potential solutions to address these disparities.

Contributors NQPT and RJV contributed to the conception of the paper, critically read and modified subsequent drafts, and approved the final version.

Funding RJV was supported by grants from the Cancer Prevention and Research Institute of Texas (CPRIT, RP190210), and The University of Texas MD Anderson's Cancer Center Support Grant funded by the National Cancer Institute (P30CA016672) using the Shared Decision Making Core and Clinical Protocol and Data Management System. NQPT's research is supported by the CPRTP at MD Anderson Cancer Center and the CPRIT Postdoctoral Fellowship in Cancer Prevention (RP 170259, Drs Shine Chang and Sanjay Shete, principal investigators).

Competing interests None declared.

Patient consent for publication Not required.

Provenance and peer review Commissioned; internally peer reviewed.

\section{REFERENCES}

1 Birkeland S, Bismark M, Barry MJ, et al. Is greater patient involvement associated with higher satisfaction? experimental evidence from a vignette survey. BMJ Qual Saf 2021.

doi:10.1136/bmjqs-2020-012786. [Epub ahead of print: 22 Apr 2021].

2 Enard KR, Dolan Mullen P, Kamath GR, et al. Are cancerrelated decision AIDS appropriate for socially disadvantaged patients? A systematic review of US randomized controlled trials. BMC Med Inform Decis Mak 2016;16:1-15.

3 Schoenfeld EM, Goff SL, Downs G, et al. A Qualitative Analysis of Patients' Perceptions of Shared Decision Making in the Emergency Department: "Let Me Know I Have a Choice". Acad Emerg Med 2018;25:716-27.

4 Peek ME, Odoms-Young A, Quinn MT, et al. Racism in healthcare: its relationship to shared decision-making and health disparities: a response to Bradby. Soc Sci Med 2010;71:13-17.

5 Pérez-Stable EJ, El-Toukhy S. Communicating with diverse patients: how patient and clinician factors affect disparities. Patient Educ Couns 2018;101:2186-94.

6 King JS, Eckman MH, Moulton BW. The potential of shared decision making to reduce health disparities. J Law Med Ethics 2011;39 Suppl 1:30-3.

7 Towle A, Godolphin W, Greenhalgh T, et al. Framework for teaching and learning informed shared decision making Commentary: Competencies for informed shared decision making Commentary: Proposals based on too many assumptions. BMJ 1999;319:766-71.

8 Elwyn G, Edwards A, Kinnersley P, et al. Shared decision making and the concept of equipoise: the competences of involving patients in healthcare choices. Br J Gen Pract 2000;50:892-9.

9 Thériault G, Bell NR, Grad R, et al. Teaching shared decision making: an essential competency. Can Fam Physician 2019;65:514-6.

10 Lenzen SA, Daniëls R, van Bokhoven MA, et al. What makes it so difficult for nurses to coach patients in shared decision making? A process evaluation. Int J Nurs Stud 2018;80:1-11.

11 Afifi TD, Olson LN, Armstrong C. The chilling effect and family secrets: examining the role of self protection, other protection, and communication efficacy. Human Communication Research 2005;31:564-98.

12 Reyna VF, Nelson WL, Han PK, et al. How numeracy influences risk comprehension and medical decision making. Psychol Bull 2009;135:943-73.

13 Walsh-Childers K, Braddock J. Competing with the conventional wisdom: newspaper framing of medical overtreatment. Health Commun 2014;29:157-72.

14 Vannier MW. Screening mammography: what good is it and how can we know if it works? J Natl Cancer Inst 2012;104:1039-40.

15 Scherer LD, Valentine KD, Patel N, et al. A bias for action in cancer screening? J Exp Psychol Appl 2019;25:149.

16 Bekker HL, Winterbottom AE, Butow P, et al. Do personal stories make patient decision AIDS more effective? A critical review of theory and evidence. BMC Med Inform Decis Mak 2013;13:1-9.

17 Shaffer VA, Brodney S, Gavaruzzi T, et al. Do personal stories make patient decision AIDS more effective? an update from the International patient decision AIDS standards. Med Decis Making 2021;0272989X:211011100. 


\section{Editorial}

18 Green MC. Narratives and cancer communication. J Commun 2006;56:S163-83.

19 Slater MD. Entertainment education and the persuasive impact of narratives, 2002. https://psycnet.apa.org/record/200304381-007

20 Moyer-Gusé E, Chung AH, Jain P. Identification with characters and discussion of taboo topics after exposure to an entertainment narrative about sexual health. J Commun 2011;61:387-406.

21 Slater MD, Rouner D. Entertainment-education and elaboration likelihood: understanding the processing of narrative persuasion. Communication theory 2002;12:173-91.

22 Patel VL, Kaufman DR, Arocha JF. Emerging paradigms of cognition in medical decision-making. J Biomed Inform 2002;35:52-75.

23 Alden DL, Friend J, Schapira M, et al. Cultural targeting and tailoring of shared decision making technology: a theoretical framework for improving the effectiveness of patient decision AIDS in culturally diverse groups. Soc Sci Med 2014;105:1-8.

24 Peek ME, Quinn MT, Gorawara-Bhat R, et al. How is shared decision-making defined among African-Americans with diabetes? Patient Educ Couns 2008;72:450-8.

25 Mead EL, Doorenbos AZ, Javid SH, et al. Shared decisionmaking for cancer care among racial and ethnic minorities: a systematic review. Am J Public Health 2013;103:e15-29.

26 Thomson MD, Hoffman-Goetz L. Readability and cultural sensitivity of web-based patient decision AIDS for cancer screening and treatment: a systematic review. Med Inform Internet Med 2007;32:263-86.

27 Chenel V, Mortenson WB, Guay M, et al. Cultural adaptation and validation of patient decision AIDS: a scoping review. Patient Prefer Adherence 2018;12:321-32. 